\title{
PERFIL DO CONSUMIDOR BRASILEIRO E HÁBITOS DE CONSUMO DE LEITE E DERIVADOS
}

\section{(Profile of the Brazilian consumer and consumer habits of milk and dairy products)}

José Carlos Ribeiro Júnior ${ }^{1}$, Isac Gabriel Cunha dos Santos ${ }^{1}$, Bianca Pereira Dias ${ }^{1}$, Letícia Ponce Mendes $^{2}$, Ana Paula Ayub da Costa Barbon ${ }^{2}$

\author{
${ }^{1}$ Laboratório de Microbiologia de Alimentos, Universidade Federal do Tocantins, Campus \\ Universitário de Araguaína, Araguaína, Tocantins, Brasil, ${ }^{2}$ Centro Universitário Filadélfia (UniFil), \\ Londrina, Paraná, Brasil
}

Corresponding author: ribeirojuniorjc@gmail.com

RESUMO: Objetivou-se verificar o perfil do consumidor brasileiro de leite e derivados, os hábitos de consumo e o seu esclarecimento quanto a qualidade nutricional, sanitária e do serviço de inspeção desses produtos. Foi elaborado um questionário pela ferramenta Google Formulários e enviado pelo meio eletrônico no qual obteve-se 2.052 respostas, que consolidaram $99,9 \%$ de confiança. Foram questionados sexo, idade, escolaridade, consumo de leite, predileção por produtos lácteos, local de compra, diferença entre derivados, importância do consumo e sobre o selo de inspeção. Os dados mostraram que $89 \%$ dos entrevistados consomem o leite fluido, sendo que $83,5 \%$ preferem leite longa vida, 92,3\% preferem o queijo como derivado, $72,7 \%$ adquirem o leite no supermercado. Dos consumidores que adquirem regularmente leite cru $(7,3 \%), 77,3 \%$ afirmam não realizar nenhum tratamento térmico que Ihe confira segurança microbiológica. Quando questionados se o leite é um alimento saudável, $85,4 \%$ o consideram, em contrapartida $70,8 \%$ acreditam que o leite pode trazer algum risco a saúde, sem ciência dos tratamentos térmicos que Ihe conferem segurança para o consumo. Sobre a ingestão semanal, $38,2 \%$ consome mais de cinco vezes. Sobre os símbolos de inspeção sanitária nas embalagens, $34 \%$ não sabem o significado, podendo-se inferir que esses consumidores são susceptíveis a aquisição de produtos clandestinos e que podem oferecer risco. Conclui-se que existe ainda falta de esclarecimento do consumidor sobre a qualidade nutricional e sanitária do leite e derivados e precisa-se realizar programas de conscientização que visem a minimização de perigos sanitários de produtos clandestinos.

Palavras-chave: Produtos de origem animal; produtos lácteos; queijo; serviço de inspeção.

ABSTRACT: The objective was to verify the profile of the Brazilian consumer of milk and dairy products, consumption habits and their clarification regarding the nutritional, health and inspection quality of these products. A questionnaire was prepared using the Google Forms tool and sent electronically, in which 2,052 responses were obtained, which consolidated $99.9 \%$ confidence. Sex, age, education, milk consumption, predilection for dairy products, place of purchase, difference between derivatives, importance of consumption and the inspection seal were questioned. The data showed that $89 \%$ of respondents consume fluid milk, $83.5 \%$ prefer long-life milk, $92.3 \%$ prefer cheese as a derivative, $72.7 \%$ purchase milk at the supermarket. Of the consumers who regularly purchase raw milk, $77.3 \%$ say they do not undergo any heat treatment that gives them microbiological safety. When asked if milk is a healthy food, $85.4 \%$ consider it, in contrast $70.8 \%$ believe 
that milk may bring some risk to health, without being aware of the heat treatments that make it safe for consumption. About weekly intake $38.2 \%$ consume more than five times. Regarding the symbols of sanitary inspection on the packaging, $34 \%$ do not know the meaning, and it can be inferred that these consumers are susceptible to the acquisition of clandestine products. In conclusion, there is still a lack of clarification from the consumer about the nutritional and health quality of milk and dairy products, and awareness programs are needed to minimize the health hazards of clandestine products.

Keywords: Animal products; dairy products; cheese; inspection service. 


\section{INTRODUÇÃO}

O leite é um dos produtos oriundos da pecuária mais relevantes dentro do comércio mundial. Estima-se que um bilhão de pessoas vivem do trabalho com o leite em diversas fazendas e indústrias leiteiras ao redor do mundo (EMBRAPA, 2017).

Além da sua importância econômica, o leite é indispensável para a dieta humana devido ao seu alto teor nutricional (RAYMUNDO et al., 2017). Por outro lado, os constituintes desse alimento são sensíveis à ação microbiana e, como consequência, afeta-se a sua qualidade, potencial tecnológico e valor nutricional (CHEN et al., 2003; CASTRO et al., 2014). A contaminação microbiológica do leite é advinda das condições insatisfatórias de higiene no processamento e/ou na ordenha e podem comprometer a sua segurança para consumo (DURR et al., 2004; SOUZA, 2019).

A qualidade do leite também está ligada diretamente à sanidade animal, uma vez que o leite pode ser um mecanismo de transporte para patógenos zoonóticos (CALLEFE, LANGONI, 2015). Muitos patógenos causadores de doenças transmitidas por alimentos podem ser transmitidos por leite e derivados crus, principalmente os comercializados clandestinamente (CAMPOS et al., 2018; RIBEIRO JÚNIOR et al., 2019). Portanto, a ausência da qualidade $\mathrm{e}$ inspeção sanitária, faz do leite cru não inspecionado um produto impróprio e com risco à saúde dos consumidores (RAYMUNDO et al., 2017).

Contudo, ainda existe a comercialização do leite cru no mercado brasileiro varejista, devido a fatores culturais e sociais, além da falta de conhecimento ou concepções errôneas do produto (SOUZA, 2019).

Como a indústria de lácteos precisa de dados para promover uma produção que atenda a demanda, a importância do leite na alimentação humana e o risco à população de produtos lácteos comercializados clandestinamente, o objetivo do presente trabalho foi verificar o perfil do consumidor brasileiro de leite e derivados, os hábitos de consumo e o seu esclarecimento quanto a qualidade nutricional, sanitária e do serviço de inspeção desses produtos.

\section{MATERIAL E MÉTODOS}

Para avaliação do perfil do consumidor foram questionadas a idade, sexo, estado de residência, moradia em área urbana ou rural e escolaridade. Todas as repostas foram obtidas através de marcações simples em campos pré-estabelecidos.

Os hábitos de consumo de leite e/ou derivados foram avaliados por meio do questionamento se há o consumo, ou o motivo de não consumir, qual o tipo de produto e a frequência que consome. Também foi verificado o esclarecimento do consumidor quanto ao aspecto nutricional, sanitário e do serviço de inspeção de leite e derivados. O formulário aplicado encontra-se como material suplementar a esse manuscrito.

O questionário foi elaborado pela ferramenta Google Formulários (https://docs.google.com/forms) e encaminhado eletronicamente com ampla difusão via redes sociais (Instagram, Facebook e WhatsApp) entre 23 de abril a 04 de maio de 2018. A popularização do link de acesso foi apoiada pelos acadêmicos em Medicina Veterinária do Centro Universitário Filadélfia (UniFil) de Londrina, Paraná. A adesão ao preenchimento foi voluntária, randômica e ao acaso.

Para cálculo da unidade amostral (número mínimo de repostas ao formulário) foi utilizada a ferramenta online Calculator.net (https://www.calculator.net/sample-sizecalculator.html), com nível de confiança 
de $99,9 \%$, margem de erro de $5 \%$ e tamanho da população estimado em 208 milhões de brasileiros na época de aplicação do questionário.

\section{RESULTADOS E DISCUSSÃO}

De acordo com os cálculos de amostragem, esperava-se no mínimo 1.083 respostas ao formulário. Como foram recebidas 2.052, atendeu-se a quase o dobro da amostragem mínima para obtenção de resultados com nível de confiança de $99,9 \%$ em relação ao total estimado da população brasileira.

Quanto ao perfil dos consumidores que responderam ao formulário, $70 \%$ foram mulheres e $30 \%$ homens. Cerca de $52,5 \%$ do total pertenciam a faixa etária de 19 a 35 anos. A distribuição etária dos consumidores que responderam a esse questionário está representada na Figura 1.

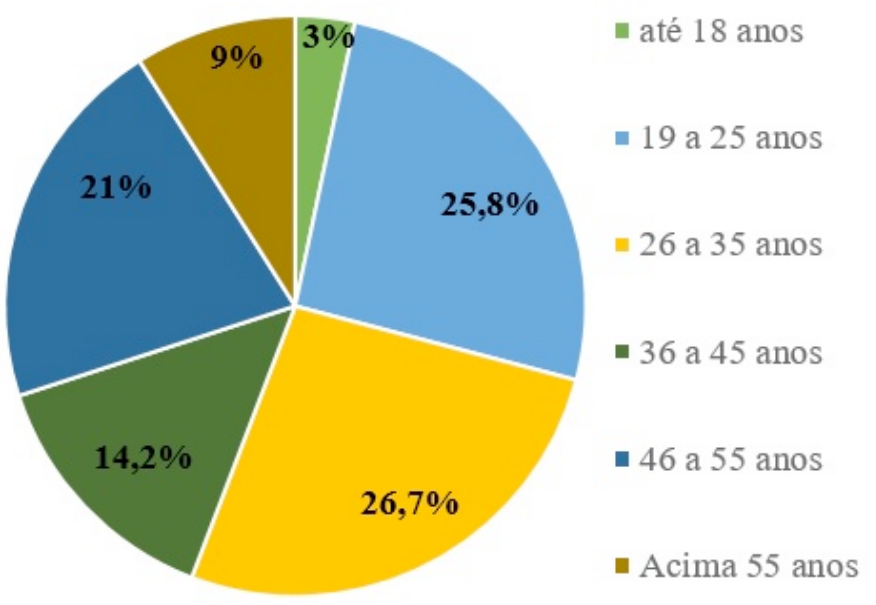

Figura 1. Distribuição etária de 2.052 pessoas que responderam voluntariamente ao questionário sobre consumo de leite e/ou derivados.

Quanto a distribuição dos consumidores que aderiram a esse formulário pelos estados brasileiros, foi possível observar que houve predomínio de respostas de consumidores da região sul, considerando que a divulgação maior ocorreu primariamente na rede de contatos de graduandos da cidade de Londrina, estado do Paraná. Somente nesse estado foram observadas 1.481 respostas, o que representa $72,17 \%$ do total. No entanto, foram observadas respostas oriundas de todas as unidades federativas do Brasil, estando todas as regiões do país representadas no presente trabalho, conforme pode ser verificado na Figura 2.

Ainda em relação ao perfil dos consumidores que responderam ao questionário, foi observado que $96,2 \%$ residem na região urbana. Os dados estimados pelo Instituto Brasileiro de Geografia e Estatística (IBGE, 2017) apontam que a população urbana brasileira seja de $84,3 \%$, portanto, os resultados gerais obtidos pelo presente trabalho representam a maioria dos consumidores residentes em áreas urbanas.

O grau de escolaridade observado foi de $4,4 \%$ para primeiro grau, $19,2 \%$ segundo e $53,3 \%$ para ensino superior.

Quanto aos hábitos de consumo, $89 \%$ das respostas apontavam o consumo regular de leite fluido. As apresentações comerciais mais consumidas de leite fluido, em ordem decrescente, são: Ultra High 
Temperature (UHT) $(83,5 \%)$, em pó $(21,1 \%)$, saquinho/pasteurizado $(18 \%)$ e leite cru (garrafas pet - 7,3\%). Nessa categoria, os consumidores poderiam marcar mais de uma apresentação comercial.

De acordo com a Pesquisa Industrial Anual (PIA) de 2018 do IBGE, - leite UHT foi $028^{\circ}$ produto industrializado mais comercializado no Brasil. Sozinho, representa $23,1 \%$ do comércio nacional de lácteos (IBGE,
2019). Isso se deve principalmente pela longa vida útil e conservação em temperatura ambiente.

Sabe-se que, para a indústria, a produção de leite UHT é mais conveniente, pela vida útil média de quatro meses e economia de energia em relação ao leite pasteurizado, que necessita ser refrigerado. Tudo isso facilita a logística de distribuição do produto em todo o território nacional.

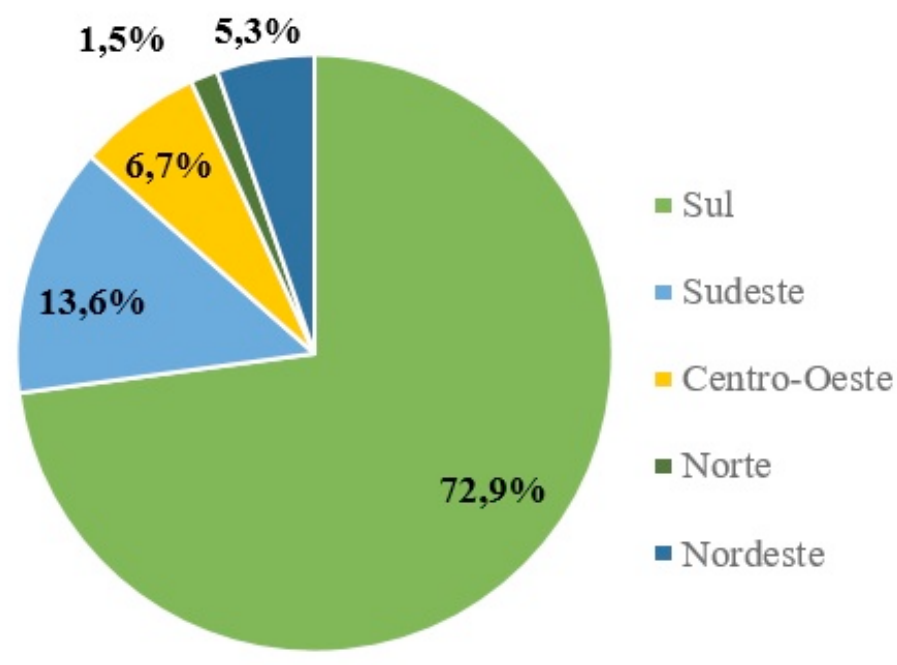

Figura 2. Distribuição por região do Brasil de 2.052 pessoas que responderam voluntariamente ao questionário sobre consumo de leite e/ou derivados.

No entanto, o tratamento térmico elevado pode interferir nas propriedades nutricionais e, principalmente, biológicas do leite, como a queda de cálcio livre e a morte de bactérias termodúricas probióticas, respectivamente (BELOTI, 2015).

A Instrução Normativa $\mathrm{N}^{\circ} 76$, de 26 de novembro de 2018 (BRASIL, 2018), legislação brasileira que atualmente regulamenta a produção e o processamento de leite e derivados no país, proíbe a comercialização direta ao consumidor de leite ou derivados crus sem algum tipo de tratamento térmico que confira segurança microbiológica, como a pasteurização e o tratamento UHT.
No entanto, principalmente pequenos produtores, com o objetivo de aumentar a sua lucratividade, vendem leite cru ou derivados crus diretamente a os consumidores, principalmente 0 queijo tipo Minas Frescal (RIBEIRO JÚNIOR et al., 2019). Alguns profissionais de saúde, inclusive, vêm recomendando que os consumidores busquem produtores da região para comprar leite. Isso, além de ilegal, expõe a população ao risco de contrair zoonoses como a brucelose e a tuberculose, além de inúmeros outros patógenos microbianos de origem alimentar, como bactérias dos gêneros Salmonella, Shigella, Yersinia, Listeria e Escherichia coli (BELOTI, 2015). 
Os outros $11 \%(\mathrm{n}=256) \mathrm{de}$ respostas justificaram a ausência de consumo de leite em virtude principalmente de intolerância à lactose $(24,7 \%)$, falta de hábito $(12 \%)$ ou não gostar do sabor (11\%). A opção pelo veganismo e alergia a caseína também foram citadas. Atendendo a demanda de quase $25 \%$ da população que relata ter problemas de intolerância à lactose, os laticínios já produzem uma ampla diversidade de produtos sem 0 dissacarídeo, que tecnologicamente são obtidos após a adição de lactase ao leite, desfazendo-se a ligação entre os monossacarídeos galactose e glicose (BELOTI, 2015). Um estudo regional demostrou um percentual maior em relação a negativa do consumo do leite devido a intolerância a lactose: $48,57 \%$ em Maringá-PR (MOLINA et al., 2010). Enquanto isso, apenas $2,74 \%$ no Vale do Rio São Francisco (LIRO et al, 2011) relataram não consumir leite por intolerância.

Também foram observadas algumas alegações controversas para não consumir leite fluido, como perda de confiança na qualidade do leite UHT, crises depressivas após o consumo de leite, o consumo de leite pode fazer mal à saúde, causar labirintite, proibição médica e retirada da dieta por nutricionistas, entre outras.

O estudo de Pierri et al. (2014) relata que $18,5 \%$ dos brasileiros entrevistados em Minas Gerais adquirem regularmente leite e derivados crus sem qualquer tipo de tratamento térmico ou processo tecnológico que confira inocuidade ao alimento. Nero et al. (2003) mostraram que $33,57 \%$ da população de Campo Mourão-PR consome leite in natura (entende-se leite cru) e em Calotina - ES, Miller (2008) relata que $34,59 \%$ tem esse hábito. Dos consumidores de leite cru do presente trabalho, $77,3 \%$ não tem o hábito de ferver leite, justificado por grande parte deles por aspectos culturais em idealizarem que o consumo de leite direto da vaca é mais saudável, ou simplesmente por não terem o costume.

Dos 3,8\% (77) das pessoas que moram na região rural, 5,2\% (4) afirmam ter o hábito de consumir leite cru sem ferver, assim como afirmam consumir derivados regularmente, provavelmente também fabricados com leite cru. Isso se dá pelo fácil acesso ao leite da propriedade e a suposição de que é mais saudável, mas também pela falta de informação no que se diz respeito ao processamento e segurança do leite para o consumo.

Esses consumidores estão expostos a patógenos microbianos frequentemente relatados como veiculados pelo leite ou derivados crus (KATAFIASZ; BARTLETT, 2012). Como demonstram Bersot et al. (2010), que verificaram que mais de $75 \%$ dos consumidores entrevistados na região de Palotina- PR não estavam cientes dos problemas decorrentes do consumo de leite cru e outros $24 \%$ citaram a febre aftosa como a principal doença que pode ser transmitida pelo leite cru, seguida de brucelose, tuberculose e problema entérico.

Em relação ao consumo de derivados lácteos, os resultados do presente trabalho demonstram que 0 produto mais consumido é o queijo totalizando $92,3 \%$, também verificado nos resultados de Molina et al. (2010) com consumidores de Maringá-PR. Leite condensado $(83,6 \%)$, creme de leite $(83,1 \%)$ e manteiga $(81,3 \%)$ são em ordem decrescente os outros derivados lácteos mais consumidos, como mostra o a figura 3.

O maior consumo de queijos pode ser reflexo das variedades existentes, ofertando diversas características organolépticas, atendendo uma maior parcela do público alvo. O segundo derivado mais consumido é o leite condensado, seguido da manteiga. Talvez justificado por diversas 
preparações culinárias que os têm como um dos seus principais ingredientes.

Ainda sobre os derivados, $19,5 \%$ dos entrevistados não sabem a diferença entre manteiga e margarina, o que talvez pode ter influenciado 0 grande número de respostas relacionadas ao consumo de manteiga. Essa diferença entre os produtos deve ser esclarecida, uma vez que manteiga é um derivado de origem animal e a margarina de origem vegetal, com propriedades sensoriais semelhantes, no entanto, com diferenças significativas em relação aos conceitos tecnológicos e nutricionais (ALMEIDA et al., 2011).

Os resultados ainda revelaram que $25,5 \%$ dos consumidores de leite não sabem a diferença entre leite cru e pasteurizado, e que $77 \%$ já consumiram queijo com aparência eminente de alta contaminação por coliformes, provavelmente produzido com leite cru ou com leite pasteurizado que foi altamente contaminado por microorganismos ambientais após a pasteurização. O queijo produzido do leite cru é responsável por aproximadamente $70 \%$ dos surtos de doenças transmitidas por alimentos relacionados a laticínios (PIERRI et al., 2014). Sordi et al. (2015) avaliando o perfil do consumidor de leite na cidade de Erechim - RS relataram que grande da parte da população $(59,86 \%)$ utiliza o leite cru para preparação de doces.

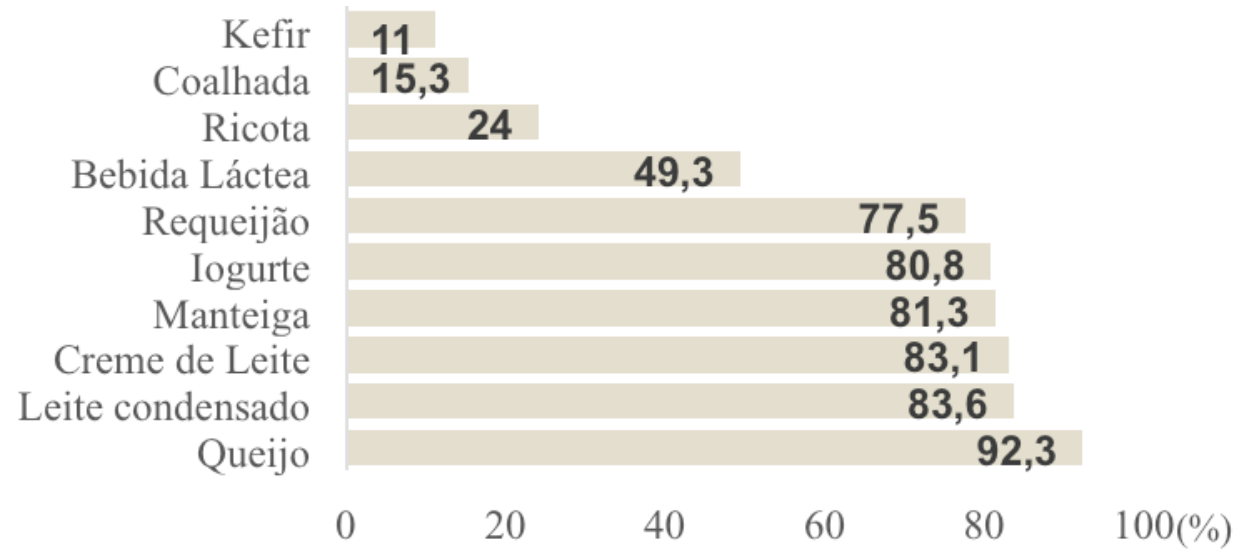

Figura 3. Relação em percentual do consumo de derivados lácteos pelos consumidores brasileiros.

Pelo desconhecimento do risco microbiológico que o consumo de leite ou derivados crus podem oferecer à saúde, é notável que essa parcela de consumidores é susceptível ao consumo desses produtos se disponíveis, uma vez que mostram falta de conhecimento sobre o processo de pasteurização como ferramenta para redução de perigos microbiológicos.

Quando questionados sobre o local de compra, $72,7 \%$ adquirem leite e queijo no supermercado, na maioria das vezes alegando uma maior confiabilidade, $6,3 \%$ na padaria, afirmando estes o fácil acesso, 3,3\% na feira, provavelmente pelo valor comprado quando comparado aos outros locais e $15,5 \%$ preferem consumir o leite advindo direto do produtor. Sordi et al. (2015) relacionam o acesso facilitado ao leite cru por familiares que possuem propriedades leiteiras.

Dois fatores que podem influenciar diretamente a qualidade do leite cru são o período de armazenamento e a temperatura (BRASIL, 2018), pois estes influenciam de forma direta na multiplicação de microrganismos. Isso dificilmente é atendido pelos produtores que comercializam leite cru ao consumidor (BERSOT et al., 2010). Dessa forma, 
tanto a deterioração microbiana do leite quanto o seu risco ao consumo são influenciados negativamente por esse comércio clandestino.

Quando questionados se o leite é um alimento saudável, $85,4 \%$ dos entrevistados pelo presente trabalho o consideraram. Apesar de $70,8 \%$ dos entrevistados acreditarem que o leite pode transmitir alguma doença, haviam consumidores que relatavam o consumo de leite cru. Vieira Liro et al. (2011) relatam que $39,3 \%$ da população de Petrolina-PE desconhecem doenças que possam ser transmitidas pelo leite.

No presente estudo $25 \%$ dos consumidores não sabem a diferença entre leite cru e pasteurizado, assim também como descrito por Molina et al. (2010) no qual $29 \%$ dos entrevistados não sabiam a diferença entre os tipos de leite. Fica evidente, portanto, a necessidade de conscientização dos consumidores quanto ao consumo de produtos inspecionados e tratados termicamente para a eliminação de perigos microbiológicos.

Sobre a frequência semanal do consumo de leite, $18,8 \%$ dos entrevistados pelo presente trabalho relatam o consumo uma vez, $11,7 \%$ duas vezes, $14,5 \%$ três vezes, $6,8 \%$ quatro vezes, $10 \%$ cinco vezes e $38,2 \%$ mais que cinco vezes.

O Ministério da Saúde, através de seu Guia Alimentar, orienta o consumo de três porções de leite e/ou derivados diárias (BRASIL, 2006). Entre os consumidores entrevistados, notavelmente a maioria atingem à essa recomendação. Os constituintes do leite atuam no metabolismo de várias formas, fornecendo aminoácidos essenciais, vitaminas, minerais e ácidos graxos, ou mesmo possibilitando a absorção de nutrientes (HAUG et al., 2007)

Quando se questionou sobre o significado dos símbolos de inspeção nas embalagens de leite ou derivados lácteos, foi verificado que $34 \%$ dos consumidores não sabem 0 seu significado e o que ele representa sobre o ponto de vista sanitário.

Este parâmetro mostra que é preciso ainda o fomento para educação sanitária, e que a ausência deste conhecimento pode levar os consumidores a adquirirem um produto com risco microbiológico comprometendo a sua saúde.

\section{CONCLUSÕES}

Os consumidores brasileiros preferem adquirir o leite UHT e o queijo como o principal derivado lácteo. O leite cru tem demanda considerável pelo consumidor brasileiro, talvez por ser erroneamente recomendado por profissionais. O conhecimento sobre a importância da inspeção sanitária para promoção de segurança dos alimentos precisa ser melhor divulgado. São necessárias pesquisas e trabalhos de extensão para que informações sejam levadas aos consumidores e assim, possam adquirir um leite de melhor qualidade e sem risco sanitário.

\section{REFERÊNCIAS}

ALMEIDA, M. E. F.; QUEIROZ, J. H.; COSTA, N. M. B. et al. Lipídeos séricos e morfologia hepática de ratos alimentados com diferentes fontes lipídicas (óleo de soja, gordura de peixe e porco, margarina e manteiga. Revista de Nutrição 24, 143-152, jan./fev., 2011

BELOTI, V. Leite: Obtenção, Inspeção e Qualidade. $1^{\circ}$ ed. Londrina: Editora Planta, 2015.

BERSOT, L. D. S.; DAGUER. H.; MASIEIRO. M. T.; PINTO. J. P. A. N.; BARCELLOS. V. C.; GALVÃO. J. A. Raw milk trade: profile of the consumers and microbiological and physicochemical characterization of the product in Palotina - PR region. Revista 
Instituto Lacticínios "Cândido

Tostes", Mar/Abr, n 373, 65 : 3-8, 2010

BRASIL. Ministério da Saúde $n^{\circ} 451$, de 19 de setembro de 1997. Estabelece padrões microbiólogicos de alimentos. Diário Oficial [da] República Federativa do Brasil, Brasília, DF, 22 de set. 1997.

BRASIL. Ministério da Saúde. Secretaria de Atenção à Saúde. Coordenação Gearl da Política de Alimentação e Nutrição. Guia Alimentar para população brasileira: promovendo a alimentação saudável. Brasília: MS; 2006 Disponível em: https://bvsms.saude.gov.br/bvs/publicac oes/guia_alimentar_populacao_brasileir a_2ed.pdf. Acesso em 12/03/2020

BRASIL. Instrução Normativa $n^{\circ} 76$, de 26 de novembro de 2018. Aprova os Regulamentos Técnicos de Identidade e Qualidade do cru refrigerado, leite pasteurizado e o leite pasteurizado tipo A. Diário Oficial da República Federativa do Brasil, Brasília, seção 1, n. 230, p.9, 30 de nov. 2018. Disponível nosite:http://www.in.gov.br/materia//asse t publisher/Kujrw0TZC2Mb/content/id/5 2750137/do1-2018-11-30-instrucao-nor mativa-n-76-de-26-de-novembro-de2018 $-52749894 \mathrm{IN} \% 2076 /$. Acessado no dia $29 / 02 / 2020$

CALLEFE, J.L.R.; LANGONI, H. Qualidade do leite: uma meta a ser atingida. Veterinária e Zootecnia 22, 151-161, 2015.

CAMPOS, A. C., J. J. PUÑOSARMIENTO, L. P. MEDEIROS, L. E., et al. Virulence Genes and Antimicrobial Resistance in Escherichia coli from Cheese Made from Unpasteurized Milk in Brazil. Foodborne Pathogens and Disease 15, 94-100, 2018.

CASTRO, K. A., SILVA, K. A. L., PEREIRA A. I. A. et al. Efeito da contagem de células somáticas sobre a qualidade dos queios prato e mussarela
Revista Brasileira de Tecnologia Agroindustrial 8, 1237-1250, 2014

CHEN, L DANIEL, R. M. COOLBEAR T. Detection and impacto $f$ protease and lipase actives in milk and milk powders. International Dairy Journal 13, 255275, 2003

DÜRR, J.W. Programa nacional de melhoria da qualidade do leite: uma oportunidade única. In: DÜRR, J.W. et al. (Ed.). $\mathrm{O}$ compromisso com a qualidade do leite no Brasil. Passo Fundo: UPF, 2004. 331p

EMBRAPA - Empresa Brasileira de Pesquisa Agropecuária. O Mercado Consumidor de Leite e Derivados. Julho, 2017, disponível em https://ainfo.cnptia.embrapa.br/digital/bit stream/item/199791/1/CT-120-Mercado ConsumidorKennya.pdf. Acesso em 05/01/2020.

GDP - Global Dairy Platform. Annual Review 2016. Rosemont, IL, [2017]. Disponível em: www.globaldairy platform.com $\% 2 \mathrm{~F}$ wpcontent $\% 2 \mathrm{~F}+$ upload s\%2F2018\%2F04\%2F2016-annual-revi ew-final.pdf>. Acesso em: 29/02/ 2020.

HÁUG, A.; HOSTMARK, A.T.; HARSTAD, O. M.Bovine milk in human nutrition: review. Lipds in Healh and Diasease, v. 6, p.25, 2007.

IBGE- INSITUTO BRASILEIRO DE GEOGRAFIA E ESTATISTICA. Censo Agropecuário. 2016. Disponível em: https://biblioteca.ibge.gov.br/visualizaca o/livros/liv98965.pdf. Acesso em : 12/12/2019.

IBGE- INSITUTO BRASILEIRO DE GEOGRAFIA E ESTATISTICA. Pesquisa Industrial Anual 2019. Disponível em: https://ainfo.cnptia. embrapa.br/digital/bitstream/item/19979

1/1/CT-120-MercadoConsumidorKennya .pdf. Acesso em: 11/03/2020.

KATAFIASZ A.R.; BARTLETT P. Motivation for Unpasteurized Milk 
Consumption in Michigan, Food Protection Trends, 32, 124-128, 2012.

LIRO, C. V.; GRANJA, R. E. P.; ZOCCHE, F. Perfil do consumidor de leite no Vale do Rio São Francisco, Pernambuco. Ciência

Animal

Brasileira, Goiânia, v. 12, n. 4, p. 718726, 2011. http://dx.doi.org/10.5216/cab. v12i4.11613

MILLER, N. B. Perfil do consumidor de leite e derivados lácteos do município de Colatina - ES. Instituto Brasileiro de Pós-Graduação Qualittas, abril de 2008.

MOLINA, G.; PELISSARE. F. M.; FEIHRMANN. A. C. Perfil do comsumidor de leite e produtos derivados na cidade de Maringá, Estado do Paraná, Acta Scientiarum Technology, v.32,n.3,p.327-334,2010.

PIERI, F.A.; COLOMBO, M.; MERHI, C.M. et al. Risky consumption habits and safety of fluid milk available in retail sales outlets in viçosa, Minas Gerais State, Brazil. Foodborne Pathogens and Disease, v.11, 405-409, 2014.

RAYMUNDO, N. K. L.; SANTOS, L. D.; OSAKI, S. C. Consumer profile and problems associated with uninspected raw milk consumption in western Paraná, Arquivos do Instituto Biológico, v.84, 1-8, 2017.

RIBEIRO JÚNIOR, J.C.; SILVA, F.F.; LIMA, J.B.A et al. Short communication: Molecular characterization and antimicrobial resistance of pathogenic Escherichia coli isolated from raw milk and Minhas Frescal cheeses in Brazil, Journal of Dairy Science, 102, 1085010854, 2019.

SORDI. E.; SKONIESKI. F. R.; CASTAMANN. A.; ZOCCHE. F. CONSUMER PROFILE OF MILK IN THE CITY OF ERECHIM - RS. Revista Brasileira de Tecnologia Agroindustrial, v.9, n.2: p.1836-1846, 2015
SOUZA, K.A. PRODUÇÃO E COMERCIALIZAÇÃO DO LEITE FORNECIDO PELA AGRICULTURA FAMILIAR EM CAJAZEIRAS-PB. 2019.Dissertação(Mestrado) - Centro de Ciências e Tecnologia Agroalimentar, Universidade Federal de Campina Grande, Pombal,PB. 